\title{
THE ROLE OF TECHNOLOGY IN TEACHERS' CREATIVITY DEVELOPMENT IN ENGLISH TEACHING PRACTICES ${ }^{1}$
}

\author{
Fitriah \\ (fitriahasad@yahoo.com) \\ UIN Sunan Ampel Surabaya \\ Jl. Ahmad Yani 117, Surabaya, East Java, Indonesia 60237
}

\begin{abstract}
This study investigates teachers' views on the role of technology in building their creativity during teaching practices within the context of Indonesian higher education. An exploratory mixed methods design was employed by interviewing $20 \mathrm{EFL}$ teachers about the role of technology in teachers' creativity and administering a creativity questionnaire to 175 teachers. The findings revealed that teachers are aware of the importance of technology in creativity. Technology appears to help them explore their creativity and encourages learners' creativity in a way that it helps transfer their creativity into reality, makes the activities more authentic, and provides teaching materials on various topics. However, there is no clear evidence about how these teachers use technology in their actual classrooms. In general, the way in which technology was utilized in teaching was limited and largely influenced by other factors, such as teachers' willingness to learn, students' participation, frequent interaction, and cooperation. This implies the need for future research to investigate the creative pedagogy of technology use in the classroom to contribute to improving classroom practices with regard to creativity and technology use.
\end{abstract}

Keywords: teachers' creativity, role of technology, English teaching practices

DOI: http://dx.doi.org/10.15639/teflinjournal.v29i2/177-193

\footnotetext{
${ }^{1}$ This article is based on a paper presentation at the 65 th TEFLIN International Conference at Universitas Negeri Makassar on 12-14 July 2018.
} 
The term 'technology' is defined as the rational craft or skill to produce something or achieve a goal which provides a means for creativity (Charlile \& Jordan, 2012). This concept of technology is often aligned with the construct of creativity which views creativity as the ability to act and perform in a particular way to achieve a goal. Although the concept of creativity itself is still undefined, people are generally able to recognise the creative acts or behaviours when they see it (Amabile, 1996; Maley, 2015). The difficulty in defining this concept occurs because the quality of creativity is presented in different ways (Maley, 2015) and creativity also has different connotations depending on the context within which it is viewed (Cropley, 2001).

In this paper, I adopt the two definitions of creativity, 'democratic' definition (NACCCE, 1999) and 'little c creativity' or LCC (Craft, 2005) to identify teachers' creativity in the use of technology in teaching. These two concepts of creativity are more relevant as the two concepts view creativity as the natural capacity that all people have. Based on these two concepts, every EFL teacher has the ability to be creative in their area of relevant knowledge and skills including creativity in the use of technology. The rapid development of technology has presented a challenge for classroom integration (Zhao, 2012) and this supports the idea of creativity as the process to construct everyday creativity (Charlile \& Jordan, 2012). Referring back to the two concepts of creativity adopted in this study, there is the possibility for the teachers to construct everyday creativity through the implementation of technology in their teaching practice. Technology does not provide the ideas; technology can complement skills by providing a means of experimentation and exploration (Charlile \& Jordan, 2012). For example, the technology of the digital camera has enhanced people's visual creativity and the sophistication of home digital recording has enabled people to create and manipulate music as if it is in the professional recording studios. Thus, this depends on the teachers how they avail themselves to find technology that can help their tasks.

In today's technology-driven world, teachers may no longer be the sole keepers of knowledge in the classroom. The introduction of one-to-one initiatives, online classrooms, blended-learning models, and the overall rise of technology in the classrooms allow students to have more access to information than past generations. Technological change is driven by human creativity, and in turn provides new contexts and tools for creative output (Henriksen, Mishra $\&$ Fisser, 2016). Given this view of the relationship between creativity and technology, it implies that teaching and learning should emphasize their con- 
nection. Teachers, however, are more important than ever in preparing students with infinite access to all types of information. Teachers can be the guides that shape educational experiences for their students, helping them engage with learning tools that will enrich and support deeper learning, including different types of technology.

In language teaching and learning, teachers' guidance is very important as they are able to combine language acquisition with primary socialisation and enculturation (Gee, 2016). This is because when students acquire a new language, they feel that they are 'outsiders' and teachers play a role as cultural brokers that help students learn the language comfortably. According to Chappell (2016), creativity has a function to explore learners' life experience. The richer the classroom is in developing and supporting this experience for the learners, the greater potential for creativity to occur. The language classroom is, therefore, a site with great potential to draw out all learners' experiences and to use the new language.

A number of studies have investigated the creativity and technology in language learning (see, e.g., Chao, 2009; Chick, 2016; Furlong \& Davies, 2012). Chao (2009) examined teachers' views of creativity in Taiwanese higher education with the participation of eight EFL teachers. Using qualitative data analysis, Chao found that the teachers applied creative strategy by connecting teaching content and real life with the purpose of linking learning to the real world and bringing the authentic world to the classroom. These teachers used technology such as Internet, and Wikispaces to create authentic situations. This finding corresponded with other creativity studies in general education that also identified the authenticity in learning context (Cheung, 2012; Horng, Hong, Chanlin, Chang, \& Chu, 2005; Schacter, Thum \& Zifkin, 2006). It is unavoidable that teaching with technology can deepen students' learning by supporting instructional objectives. However, it can be challenging for teachers to select the 'best' teaching tools for students' learning. Particularly, at the present learners have control of everyday technology which is driven by their interest in digital practices (Chick, 2016). Ideally, teachers should also understand how to use or integrate technology in teaching in order to align with the students' interest in digital practices. This research aims to examine the role of technology in teachers' creativity by identifying their perceptions about the functions of technology and the types of technology they use. The study also examined in what ways technology could build teachers' creativity. The findings will in- 
form other EFL teachers on how they should integrate the technology in their teaching practice and in what ways the use of technology could build creativity.

\section{METHOD}

The research I discussed here is a part of a larger study aimed at understanding teachers' beliefs about creativity in EFL classrooms including the characteristics of creative teachers, creative teaching practices, and the use of technology in teachers' creativity. In this article, I focus on the role of technology in developing teachers' creativity. To answer this question, the study used an exploratory mixed methods design which commences with qualitatively exploring a topic before building to a second quantitative phase (Creswell \& Clark, 2011). The study used semi-structured interviews to $20 \mathrm{EFL}$ teachers to have the flexibility to develop questions based on the participants' responses (Gall, Gall \& Borg, 2007). The questions raised include the type of available resources that improve teachers' teaching techniques, whether the teachers use the resources, and the implementation of technology in teaching. These teachers were selected purposefully based on three criteria: (1) teaching in nonEnglish departments; (2) having ELT qualifications; and (3) having at least two years of teaching experience. This study sets up these three criteria for some reasons. First, the study only involved teachers who teach ELT to the students majoring in subjects other than English, such as science, economics, and engineering as the level of motivation of these students may be different from students majoring in English. Thus, teachers' creativity could help cope with the challenges. Secondly, I found that many EFL teachers of non-English departments in some Indonesian universities do not have an ELT qualification. They are employed because they graduated from overseas. As my study identified teachers' creativity, this ELT qualification is important in guaranteeing the knowledge and skills required to teach ELT. Third, I assumed that teachers with at least two years of teaching experience would have a better understanding of how to teach creatively as opposed to teachers with no experience. With these criteria, I hope to obtain rich and comprehensive information about the role of technology in building teachers' creativity. The results of the interview analysis became a means to develop a questionnaire about the role of technology in creativity for later use in the second phase.

One hundred and seventy seven teachers from 17 universities were requested to complete the questionnaire. The questionnaire questions consist of 
both closed and open-ended items. Close-ended questions were in the form of Likert scale items and choosing one of the options. In the Likert scale items, the participants were asked to choose whether they agree or disagree with four statements about the role of technology in creativity, namely: (1) technology is a supporting tool that allows teachers to be creative in teaching; (2) technology makes the teaching interesting; (3) technology provides good teaching material; and (4) technology brings various issues from the online world into the classroom. The participants were also required to choose one of the five options for the frequency of technology use. The open responses required the participants to specify the technology that they commonly use in teaching.

Before administering the questionnaire, I piloted the questionnaire with 30 EFL teachers not participating in the main study. The typical sample size is a minimum of around 30 participants in order to run item analysis (Dörnyei, 2003). The results of the pilot-testing showed that the Cronbach's Alpha of the scale was .642; this value was not high, but acceptable (DeVellis, 2012). However, I dropped one item, 'technology from the Internet provides resources and authentic materials', as the result of Corrected Item-Total Correlation was low for this item, with a value of .058 (Field, 2013; Pallant, 2013). This indicates that the item is measuring something different from the scale as a whole (Pallant, 2013). The removal of this item also resulted in a significant improvement for the Cronbach's Alpha of the scale from .642 to .805, and this value is considered very high internal consistency reliability (DeVellis, 2012). Another reason for removing the item was that 'technology from the Internet provides resources and authentic materials' has similar meanings to other items. The statement in part can be reflected either in 'technology provides good teaching materials' or 'technology brings various issues from the online world into my classroom'.

The qualitative data were analyzed using a thematic analysis (Braun \& Clarke, 2006; Flick, 2014). The first step of the analysis was getting familiar with the data by transcribing the interviews. This process allowed me to develop first insight into the data. Then, I read through the entire dataset and gave notes or codes to the statements. The notes or codes represent the content or meaning of the participants' statements, for instance, I wrote 'utilizing technology for imaginary travelling, technology facilitates teaching and learning process, and being creative is not dependent on facilities'. This was a recursive process where I involved a constant moving back and forward between the entire dataset. I did the same process for the 20 interview transcripts. Then, I 
compiled a 'codebook' that comprised the coding list from 20 interviews and grouped them into several categories. Some codes were grouped into one category if they have a similar meaning.

The questionnaire data were analyzed descriptively using SPSS (Field, 2013; Pallant, 2013) to obtain an overview and to generalize the qualitative findings of the role of technology in building teacher creativity. The percentage and frequency of participants' responses on the role of technology were also calculated. The mean and standard deviation were calculated to examine the highest or the lowest scores of the chosen items. To simplify the analysis, the mean scores of the participants' responses (Likert scales items) were divided into categories: high (from 3.67-5.00), medium (from 2.34-3.66), and low value mean (from 1-2.33) (Al-Nouh, Abdul-Kareem, \& Taqi, 2014).

\section{FINDINGS AND DISCUSSION}

\section{Findings}

The research indicated that the use of technology in teaching brings a positive effect on teachers' creativity. To explore their creativity, teachers utilize different technological tools in their creative practices. The following section describes the common technology used and why they use technology in their creative practices.

\section{The Use of Technology}

The results of interview and questionnaire showed that teachers used a wide range of technological tools to explore their creativity in the classroom including laptop, computer, LCD (Liquid Crystal Display) projector, recorder, Internet, power points, and videos. These types of technology were classified into three categories: hardware, Internet and audio-visual materials. The use of YouTube, Google and social media comes under the 'Internet' category. 'Audio-visual materials' category includes videos and PPTs. 'Hardware' refers to the computer, laptop, video recorder and LCD projector. The questionnaire data revealed that out of all the technological tools, the hardware was the most common technology use in the classroom with $156 \%$ responses. The Internet, however, was the least common technology use with $22.6 \%$ responses. The re- 
sponses were more than $100 \%$ as one participant gave more than one responses (see Figure 1).

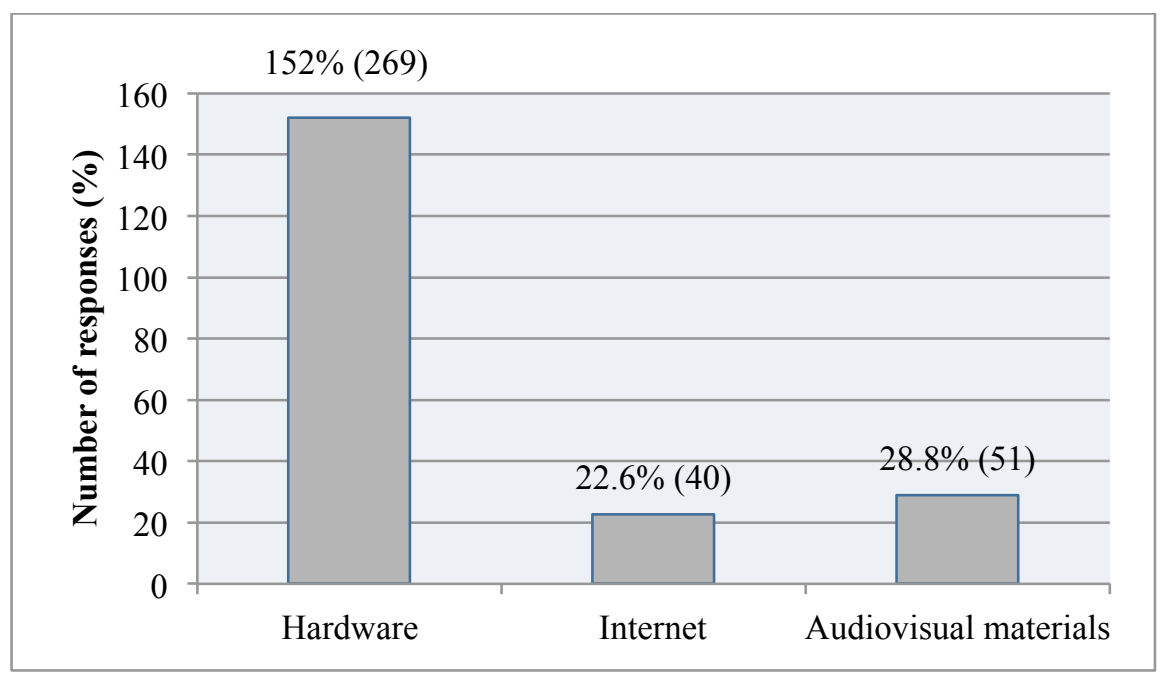

Figure 1. Types of Technology Use

This finding confirms the qualitative results which indicated that teachers acknowledged the use of the Internet in their creative practices. However, they did not use the Internet live in the classroom, instead, they used the Internet outside the classroom to prepare their teaching. For this reason, the Internet becomes the least common technology use in the classroom. Any technological tools these teachers used seem to bring a positive effect on their practices, audio-visual materials and hardware assist teachers to transform the information easily. The Internet allows teachers to obtain additional materials for their creative practices, such as video recordings of native speakers.

Relating to technology, usually, I use power points and the Internet (e.g. YouTube). I cannot browse lively in the class because the Internet access is not really good. I usually browse it at home, such as video of native speakers from YouTube on certain topics. (Rani, T66)

I really need to use the Internet because the library provides limited resources. I use the Internet not in the classroom, not during the teaching and learning process but I use it outside the classroom. (Nanda, T224) 
I need the Internet to do research for a class debate. I don't teach it but I supervise the students on how to do the research. For example, when they are doing the debate, they need to search the source. (Randy, T134)

Although it was the least common technology use in the classroom, the Internet, such as videos from YouTube, Google, social media, helped transform teachers' creativity into reality and support their teaching. Rani used videos of native speakers from YouTube for her students to learn the accent, intonation and word choice of the natives (T32). Maya needed the Internet, particularly when she asked students to do the imaginary travelling. For this purpose, the students would google the information about the most beautiful places they wanted to visit and pretended to book the flight and hotel (T54). Maya utilises the Internet technology to encourage students to experience real situation/condition about virtual travelling. This indicates that the implementation of technology depends on the purposes of the teaching. Technology helps transform the information meaningfully and perform the activities interestingly. For example, Maya's creativity works well with the assistance of technology. The students may not be able to make an online booking and to search the accommodation suitable for their budget if there is no Internet technology. Thus, technology is a bridge to transform Maya's ideas or creativity into reality. These examples imply that the use of the Internet technology is a tool to express teachers' creativity.

\section{Role of Technology}

The interview data indicated that teachers acknowledged the use of technology in their teaching with different purposes: to complement their teaching, to create real-life activity, to communicate and discuss, to encourage students in learning, and to find resources or teaching materials.

Two teachers reported that technology was complementary to teaching and that technology did not do the teachers' job. Any technology teachers used only helped and facilitated the teaching and learning process (Maya, T56). Maya gave an example of what she meant by complementary to teaching. Technology helped transfer her ideas into reality particularly when she asked students to do 'virtual travelling'. This example has been described previously for identifying how teachers use 'Google' in teaching; however, this section highlights the function of technology as part of the teaching process. In doing 'vir- 
tual travelling', technology allowed students to explore their creativity by searching information needed for their virtual travelling. This activity worked well because of the existence of the Internet technology, and Maya did not think that she could do the same activity in the past when the Internet was uncommon or rare. Although technology is important for this activity, the use of technology is only facilitating the teaching and learning process; technology cannot do the activity as it is designed by the teachers.

Another function of technology use was to make the activity more authentic. Six teachers believed in this. Sufi, for example, described how technology helped create an authentic situation, particularly when he asked students to be reporters. In this case, students had to make a video recording of what they said to their friends (T133). Both Maya's and Sufi's examples of creativity indicate that technology is a tool to create a real situation. In Maya's example, technology not only facilitates the teaching and learning process but also creates an authentic situation in which students could experience making an online booking and finding accommodation. Sufi utilised a video recorder for students to experience being real reporters. Therefore, technology is a bridge to do the activity in an authentic situation.

Four teachers reported that they used social media, such as Facebook, mailing list and blog, for communication and discussion tools. Fauzi created Facebook and mailing list groups to communicate and discuss certain topics with his students. In the group, the students had the freedom to talk about any topic they would like to share. The main point is that the topic they discussed should not contain pornography and/or hurt other people. For Fadil, social media not only functioned as a communication tool but could also encourage students to communicate in English with less inhibition (Fadil, T235). Fadil's statement indicates that the use of social media can function as a medium for communication and discussion on both the assignments and/or particular topics. Thus, there is a broader opportunity for the students to practice their English outside the classroom through the discussion in the social media.

I use social media such as Facebook and blog to discuss certain topics with the students. My students can share any topics they want to discuss. The important thing is the topic they discuss should not contain pornography issues or hurt other people. I don't involve actively in the discussion but whenever I find urgent matters that I need to explain, I will write it on Facebook or mailing list. Once, I share cultural knowledge, for example, my students tend to use the word 'excuse me' many times without understanding the appropriate use of the term 'excuse me'. 
They think the term is exactly the same as 'nyuwun sewu (Javanese language)'. So, I explain the difference between them. (Fauzi, T40)

I teach adult learners so it's important to understand how to use the technology. That's why I create a blog for media communication. I can post certain topics or materials for the next meeting. I also ask the students to email the assignment and will give it back to the students after I check the work. (Widyawati, T68)

Yes, I utilise technology in my teaching. For example, I ask my students to email the assignment and discuss certain topics in my blog. After giving the feedback on their work, they need to revise it. They also email me if they have questions regarding their work or the subject. (Fadil, T223)

Finally, teachers used technology as a tool to find resources or teaching materials. Most teachers agreed that technology such as Internet was beneficial to obtain teaching materials. Two teachers particularly noted that the Internet helped find authentic materials. They obtained various reading texts and video of native speakers from the Internet. Interestingly, despite the positive effects of technology in developing creativity, these teachers are also aware of the limitations of technology use. Maya clearly acknowledged that being creative did not depend on facilities. A simple tool found in the classroom such as 'ball' could be the source of teachers' creativity.

I am the one who is not really technology-minded. Being creative is not at all dependent on the facilities because even garbage can be the source of your creativity. It's related to someone's intelligence. A ball owned by the students can be a very good tool to create creative teaching. So, I don't believe the one who says that creativity depends very much on the facility, especially technology such as the Internet. It can be that one but it's not the only one. Creativity is everywhere. (Maya, T50)

The questionnaire data identified what teachers believe about the role of technology in creativity. Four statements describe the role of technology in creativity, namely: technology serves as a supporting tool that allows teachers to be creative (RTC12), makes the teaching interesting (RTC2), provides good teaching materials (RTC3), and brings various issues from the online world into the classroom (RTC4). Table 1 shows that all four items have high mean

\footnotetext{
${ }^{2}$ RTC stands for role of technology in creativity.
} 
scores, ranging from 4.14 to 4.30 . Out of the four items, statement 4 obtained the highest mean score at 4.30 , in which many teachers $(92 \%)$ believed that technology brings various issues from online world into the classroom.

Table 1. Means and Standard Deviations for the Role of Technology $(\mathrm{N}=175)$

\begin{tabular}{clccc}
\hline Item & \multicolumn{1}{c}{ Statement } & M & SD & Rank \\
\hline RTC1 & $\begin{array}{l}\text { Technology is a supporting tool that allows } \\
\text { me to be creative in my teaching. }\end{array}$ & 4.21 & .619 & High \\
\hline RTC2 & Technology makes my teaching interesting. & 4.21 & .631 & High \\
\hline RTC3 & $\begin{array}{l}\text { Technology provides good teaching } \\
\text { materials. }\end{array}$ & 4.14 & .619 & High \\
\hline RTC4 & $\begin{array}{l}\text { Technology brings various issues from the } \\
\text { online world into my classroom }\end{array}$ & 4.30 & .655 & High \\
\hline & $\begin{array}{l}\text { Average total of items } \\
\text { Nem }\end{array}$ & 4.21 & .520 & \\
\hline
\end{tabular}

Note: M stands for Mean, SD is Standard Deviation

Table 2 also shows more than $80 \%$ of the teachers either definitely agreed or agreed with the four statements. To reiterate, these teachers believed that Internet helps bring various issues from the online world into the classroom and makes teaching and learning more interesting. Technology can also be used as a supporting tool for creating creative activities to learn the language.

Table 2. Teachers' Perceptions of the Role of Technology in Creativity $(\mathbf{N}=175)$

\begin{tabular}{lcccc}
\hline \multirow{2}{*}{ Options } & \multicolumn{4}{c}{ Role of Technology in Creativity } \\
\cline { 2 - 5 } & RTC 1 & RTC 2 & RTC 3 & RTC 4 \\
\hline Strongly agree & $28.6 \%$ & $32 \%$ & $24.6 \%$ & $38.9 \%$ \\
\hline Agree & $65.7 \%$ & $57.7 \%$ & $66.3 \%$ & $53.1 \%$ \\
\hline Neutral & $4 \%$ & $9.7 \%$ & $8 \%$ & $7.4 \%$ \\
\hline Disagree & $1.1 \%$ & $0.6 \%$ & $0.6 \%$ & $0 \%$ \\
\hline Strongly disagree & $0.6 \%$ & $0 \%$ & $0.6 \%$ & $0.6 \%$ \\
\hline
\end{tabular}

\section{Discussion}

The results of this study showed that teachers utilised a wide range of technological tools in their creative practices, such as a computer, mobile phone, Internet, LCD projector, and videos, and the frequency of its use might 
differ from one teacher to another. The implementation of these technological tools has different functions in teachers' creativity. For example, technology helps transfer their creativity into reality, makes the activities more authentic, and provides teaching materials on various topics. The Internet, interestingly, was the least common technology used in the classroom. Although the teachers believe that the Internet helps transform their creativity into reality, they did not use the Internet live in the classroom. They used the Internet as part of the preparation process leading up to doing the actual classroom activities. Some teachers, for instance, noted that when they did a 'class debate' or a class presentation on 'virtual travelling', they had students use the Internet to search for information in advance, and directed them on how to search and what information they needed for that activity. In these cases, the Internet does the actual process of searching for information and teachers are able to apply the activities because of the existence of the Internet. Thus, the Internet has an important part in building teachers' creativity which functions as a tool to create a real situation and to find authentic information.

Another important finding of this study is that all teachers used technology in the classroom. They seem to be aware of the importance of technology in their practices. Fautley and Savage (2007) believe that the application of technology can affect the ways teachers and students are able to work. In this case, technology has potential to transform teachers' mind views (Charlile \& Jordan, 2012) as it can open up new and authentic ways of being creative due to the features of information technology it has, including provisionality, interactivity, capacity, speed, and automatic functions (Loveless, 2002). The type of technology the teachers used in this study depends on their needs and knowledge of technology, whether they use it as a means for communication and discussion or they use it to create authentic situations. This finding, particularly in the use of technology for creating authentic situations, confirmed the results of Chao's study (2009). Chao also identified that teachers utilised Internet technology to create authenticity in the learning context, for example, using real-world tools (YouTube, movies, videos, Wikispaces), assigning an authentic task and allowing learners to work on projects. Both studies noticed that the use of technology provides refreshing and varied context to make meaningful and enjoyable learning. Another similarity of this present study and Chao's study is that the teachers involved in both studies did not use Internet technology for online activities. Teachers used the Internet as part of the preparation process towards the actual practices. 
Although this present study and Chao's study identified the same purpose of using technology, the way EFL teachers in this study used technology was different from those of Chao. A good example is when one of the teachers designed an activity called 'virtual travelling'. This teacher explored students' creativity in finding real information about the destinations, accommodation, transportation and culture of the city or country that students wanted to visit. The students were therefore allowed to have personal experience, such as, on how to search for interesting places, how to do online booking and how to make an itinerary for their virtual travelling. This activity was designed specifically to make use of technology and at the same time to explore students' creativity on how to use the information they obtained for their presentation on virtual travelling. It is a good example of displaying how creativity involves the conceptualisation and manipulation of ideas, and technology assists students in relation to data manipulation, communication, collaboration, and selfexpression (Charlile \& Jordan, 2012). Richards and Cotterall (2016) state that the creative use of technology in the classroom can support the development of imagination, problem-solving, and risk-taking on the part of teachers and students. The example above shows the importance of technology to support teachers' creativity. Teachers might have difficulties introducing this activity at the time when the Internet was not common or students were unfamiliar with how to use the Internet. It also demonstrates that technology helps actualize teachers' creativity in a meaningful and interesting way. What these teachers have done may benefit the students; for example, the way the teachers creatively use the technology could motivate students in learning and encourage their participation. Also, if the teachers are able to explore their creativity, there is the possibility that the students will be creative. Students' creative abilities are most likely developed in an atmosphere in which teachers' creative abilities are properly engaged (Jeffrey \& Craft, 2004), and the use of technology is particularly valuable in enhancing 'small c' creativity. This is because technology can promote individual creativity by providing an easy way to transform an idea into reality (Charlile \& Jordan, 2012; Fautley \& Savage, 2007).

The results of this study show a positive response to the teachers' use of technology in building their creativity. They did not use technology as the main activity, and the technology could not transform teachers' knowledge. However, as noted by the teachers in this study, while technology could not replace the teacher's job, technology helped and facilitated the teaching-learning process with the teacher as the main actor. As stated by Saljo (2010), technology is 
not an 'independent variable' that can be integrated into a system to enhance learning. Technology does not provide ideas; technology can complement skills by providing a means of experimentation and exploration (Charlile \& Jordan, 2012).

\section{CONCLUSIONS}

Indonesian teachers do use technology in the classroom but they do not use it for online activities. For example, participating teachers use the Internet as part of their preparation process leading up to doing actual activities. These teachers seem to realize that being creative does not mean solely using the Internet in the classroom. There are other technological tools they can use to create creative activities such as hardware devices and audio-visual materials. With these tools, these EFL teachers are still able to explore their creativity that and encourages learners' creativity. In this case, by using technology in their lesson planning, it helps transfer the teachers' creativity into reality, makes the activities more authentic, and provides teaching materials on various topics. However, the implementation of the technology will be meaningful or effective if the teachers know how to integrate technology into classroom activities. Also, the use of technology enables and encourages teachers to become more creative in their language teaching when there is a confluence of other variables such as teachers' willingness to learn, students' participation, frequent interaction and cooperation. Thus, technology cannot stand by itself to do the activities.

The findings of this study have a number of important implications for future practice, especially for EFL teachers and researchers. First, this current study examined the role of technology in the development of teachers' creativity. The implementation of technology as described by teachers in this study provides examples of how EFL teachers could build their creativity through the use of technology in their practice. The findings revealed that teachers are aware of the importance of technology in creativity. However, there is no clear evidence about how these teachers use technology in their actual classrooms. Thus, future research need to investigate the creative pedagogy of technology use in the classroom by doing classroom observations, and identify how the teachers integrate technology into creative classroom activities. 
Fitriah, The Role of Technology in Teachers' Creativity 191

\section{REFERENCES}

Al-Nouh, N. A., Abdul-Kareem, M., \& Taqi, H. A. (2014). Primary school EFL teachers' attitudes toward creativity and their perceptions of practice. English Language Teaching, 7(9), 74-90.

Amabile, T. M. (1996). Creativity in context. Boulder, Colo: Westview Press.

Braun, V., \& Clarke, V. (2006). Using thematic analysis in psychology. Qualitative Research in Psychology, 3(2), 77-101.

Chao, C. C. (2009). Dimensions of innovation and creativity in TESOL: Views in eight teachers from Taiwanese higher education. English Teaching and Learning, 33(2), 147-181.

Chappell, P. (2016). Creativity through inquiry dialogue. In R. H. Jones \& J. C. Richards (Eds.), Creativity in language teaching: Perspectives from research and practice (pp. 130-145). New York: Routledge.

Charlile, O., \& Jordan, A. (2012). Approaches to creativity: A guide for teachers. Maidenhead: Open University Press.

Cheung, R. H. P. (2012). Teaching for creativity: Examining the beliefs of early childhood teachers and their influence on teaching practice. Australasian Journal of Early Childhood, 37(3), 43-51.

Chick, A. (2016). Creativity and technology in second-language learning and teaching. In R. H. Jones \& J. C. Richards (Eds.), Creativity in language teaching: Perspectives from research and practice (pp. 180-195). New York: Routledge.

Craft, A. (2005). Creativity in schools: Tensions and dilemmas. New York: Routledge

Creswell, J. W., \& Clark, V. L. P. (2011). Designing and conducting mixed methods research. California: SAGE Publications.

Cropley, A. J. (2001). Creativity in education and learning: A guide for teachers and educators. London: Kogan Page.

DeVellis, R. F. (2012). Scale development: Theory and applications (3 ed.). Thousand Oaks, California: Sage Publications. 
192 TEFLIN Journal, Volume 29, Number 2, July 2018

Dörnyei, Z. (2003). Questionnaires in second language research: Construction, administration and processing. Hillsdale, NJ: Lawrence Erbaum.

Fautley, M., \& Savage, J. (2007). Creativity in secondary education. Exeter: Learning Matters.

Field, A. (2013). Discovering statistics using IBM SPSS statistics $\left(4^{\text {th }}\right.$ ed.). London: SAGE Publications.

Flick, U. (2014). An introduction to qualitative research (5 ${ }^{\text {th }}$ ed.). Los Angeles: SAGE Publications.

Furlong, J., \& Davies, C. (2012). Young people, new technologies and learning at home: Taking context seriously. Oxford Review of Education, 38(1), 4562.

Gall, M. D., Gall, J. P., \& Borg, W. R. (2007). Educational research: An introduction ( $8^{\text {th }}$ ed.). Boston: A \& B Publications.

Gee, J. P. (2016). The vexed nature of language learning and teaching. In R. H. Jones \& J. C. Richards (Eds.), Creativity in language teaching: perspectives from research and practice (pp. 63-76). New York: Routledge.

Henriksen, D., Mishra, P., \& Fisser, P. (2016). Infusing creativity and technology in $21^{\text {st }}$ century education: A systemic view for change. Educational Technology \& Society, 19 (3), 27-37.

Horng, J. S., Hong, J. C., ChanLin, L. J., Chang, S. H., \& Chu, H. C. (2005). Creative teachers and creative teaching strategies. International Journal of Consumer Studies, 29(4), 352-358.

Jeffrey, B., \& Craft, A. (2004). Teaching creatively and teaching for creativity: Distinctions and relationships. Educational Studies, 30(1), 77-87.

Loveless, A. (2002). A literature review in creativity, new technologies and learning: A report for futurelab. Bristol: Futurelab.

Maley, A. (2015). Creativity - the what, the why and the how. In A. Maley \& N. Peachey (Eds.), Creativity in the English language classroom (pp. 613). London: British Council. 
National Advisory Committee on Creative and Cultural Education (NACCCE). (1999). All our futures: Creativity, culture and education. London: DFEE.

Pallant, J. (2013). SPSS survival manual: A step by step guide to data analysis using the SPSS program ( $5^{\text {th }}$ ed.). Crows Nest, NSW: Allen \& Unwin.

Richards, J. C., \& Cotterall, S. (2016). Exploring creativity in language teaching. In R. H. Jones \& J. C. Richards (Eds.), Creativity in language teaching: Perspectives from research and practice (pp. 97-113). New York: Routledge.

Saljo, R. (2010). Digital tools and challenges to institutional traditions of learning: Technologies, social memory and the performative nature of learning. Journal of Computer Assisted Learning, 26(1), 53-64.

Schacter, J., Thum, Y. M., \& Zifkin, D. (2006). How much does creative teaching enhance elementary school students' achievement? Journal of Creative Behaviour, 40(1), 47-72.

Zhao, Y. (2012). World class learners: Educating creative and entrepreneurial students. Thousand Oaks, CA: Corwin Press. 